\title{
Density Functional Theoretical Study on Intermolecular Interactions of 3,6-Dihydrazino-1,2,4,5-tetrazine Dimers
}

\author{
Yin Hu, Hai-Xia Ma, Jun-Feng Li, Rong Gao, and Ji-Rong Song ${ }^{\dagger, *}$ \\ School of Chemical Engineering, Shaanxi Key Laboratory of Physico-Inorganic Chemistry, Northwest University, \\ Xi'an 710069, P. R. China. "E-mail: mahx@nwu.edu.cn \\ ${ }^{\dagger}$ Conservation Technology Department, the Palace Museum, Beijing 100009, P. R. China. *E-mail: songji@nwu.edu.cn \\ Received May 28, 2010, Accepted August 26, 2010
}

\begin{abstract}
Seven fully optimized geometries of 3,6-dihydrazino-1,2,4,5-tetrazine (DHT) dimers have been obtained with density functional theory (DFT) method at the B3LYP/6-311++G** level. The intermolecular interaction energy was calculated with zero point energy (ZPE) correction and basis set superposition error (BSSE) correction. The greatest corrected intermolecular interaction energy of the dimers is $-23.69 \mathrm{~kJ}^{-\mathrm{mol}^{-1}}$. Natural bond orbital (NBO) analysis is performed to reveal the origin of the interaction. Based on the vibrational analysis, the changes of thermodynamic properties from the monomers to dimer with the temperature ranging from $200.0 \mathrm{~K}$ to $800.0 \mathrm{~K}$ have been obtained using the statistical thermodynamic method. It was found that the hydrogen bonds dominantly contribute to the dimers, while the binding energies are not only determined by hydrogen bonding. The dimerization process can not occur spontaneously at given temperatures.
\end{abstract}

Key Words: 3,6-Dihydrazino-1,2,4,5-tetrazine (DHT), Intermolecular interaction, Density functional theory (DFT), Natural bond orbital (NBO) analysis, Thermodynamic property

\section{Introduction}

Research into the field of energetic materials is nowadays directed towards the synthesis and properties of compounds with high energy, high density and low sensitivity to impact and friction. High nitrogen heterocyclic compounds are good candidates for this kind of material, because of their positive enthalpy of formation, high thermal stability, and low sensitivity. ${ }^{1-8}$ Moreover, high nitrogen content makes them present high density and easily obtain oxygen balance, and the main combustion product is clean gas $\left(\mathrm{N}_{2}\right)$. Therefore, high nitrogen heterocyclic compounds are being considered as green energy materials in solid propellants, explosives, and civil combustible-gas generators. $^{7,8} 3,6$-Dihydrazino-1,2,4,5-tetrazine (DHT) is a high nitrogen heterocyclic compound with nitrogen content, oxygen balance, enthalpy of formation, density, extrapolated onset temperature $\left(\mathrm{T}_{\mathrm{e}}\right)$, theoretical specific impulse (Isp), and characteristic velocity $\left(\eta^{*}\right)$ are $78.84 \%, 78.8 \%, 535 \mathrm{~kJ} \cdot \mathrm{mol}^{-1}, 1.66 \mathrm{~g} \cdot \mathrm{cm}^{-3}$, 2212.0 K, $2308.5 \mathrm{~N} \cdot \mathrm{s} \cdot \mathrm{kg}^{-1}$, and $1465.0 \mathrm{~m} \cdot \mathrm{s}^{-1}$, respectively. ${ }^{8-11}$ Furthermore, DHT is an important intermediate to synthesize other high nitrogen heterocyclic compounds, such as 3,6-diazido-1,2,4,5-tetrazine (DAT). ${ }^{11}$

In recent years, there are more reports ${ }^{12-20}$ about synthesis and characterization of DHT, with less theoretical studies. It is known that intermolecular forces control diverse physical properties such as diffusion, aggregation and detonation. Therefore, He-ming Xiao et al.. ${ }^{21-25}$ have examined the intermolecular interactions in a series of explosives and obtained some meaningful information that is valuable for further study of energetic materials.

In this paper, we theoretically investigated the intermolecular interaction of DHT dimers. Thermodynamic properties in the dimerization process were presented. Natural bond orbital
(NBO) analyses on the dimers were also performed to probe the origin of the interactions. We firstly introduce the intermolecular interaction in investigation of tetrazine compounds, Therefore, there is an important significance to carry out studies on the intermolecular interaction of DHT dimers.

\section{Computational Methods}

The structures of DHT dimers obtained from CHEM3D software were fully optimized at the DFT-B3LYP level by the Berny method ${ }^{26,27}$ with $6-311+\mathrm{G}^{* *}$ basis set. The DFT method deals with the electron correlation but is still computationally economic. To verify the suitability of the basis set used, singlepoint calculation were further carried out for all the dimers with the aug-cc-pVDZ basis set. As shown below, the results are not greatly affected by basis set size. Natural bond orbital analysis and frequency calculations were performed on each optimized structure. Thermodynamic data and their changes upon dimerizing were derived using statistical thermodynamics based on the frequencies.

The intermolecular interaction energies of DHT dimers were evaluated from the energy difference between the dimers and monomer. The basis sets commonly used to calculate the energies are far from being saturated. As a result, each sub-system in any dimers will tend to lower its energy depending on the use of the basis set functions of the other sub-system. The energies obtained at the equilibrium geometry of the dimer for each sub-system are lower than those calculated at the same geometry with the basis set functions of the respective sub-system alone. This energy difference is the so-called basis set superposition error (BSSE) that can be checked using Boys and Bernardi's counterpoise procedure $(\mathrm{CP}){ }^{28-30}$ The corrected interaction energies were calculated as follow: 


$$
\Delta E_{\mathrm{c}}=\Delta E+\Delta E_{(\mathrm{ZPE})}+\Delta E_{(\mathrm{BSSE})}
$$

Where $\Delta E$ is interaction energy, and $\Delta E_{\mathrm{c}}$ is the corrected interaction energies.

All calculations concerning the gaseous phase were performed with the program GAUSSIAN $98 .^{31}$

\section{Results and Discussion}

Optimized geometries. Seven stable structures of DHT dimers were obtained (Figure 1). After stationary points were located, vibrational frequencies were calculated in order to astertain that each structure found corresponds to a minimum on the potential energy surfaces (no imaginary frequencies) for all structures in Figure 1. Dimers I, II, III, IV, V, VI, VII all possess the same $\mathrm{C} 1$ symmetry as the monomer. Some geometrical parameters are listed in Table 1.

For the convenience of discussion, smaller atomic numberings of sub-systems are defined as the first sub-system. In the case of dimers I-V and VII, each submolecule consists of one donor atom and one accepter atom, while in dimer VI, each submolecule consists of two donor atom and one accepter atom. Compared to the monomer, the bond lengths of all dimers change largely, and apart from dimers I and V, the changes of bond lengths for other dimers mainly occur in the near of hydrogen bond and in the tetrazine ring of the second sub-system (Table 1). For instance, the N7-H11, N6-C1 lengths of dimer II increase by $1.0 \mathrm{pm}$ and $0.8 \mathrm{pm}$, respectively, while the N7-C1, $\mathrm{N} 25-\mathrm{C} 20$ and N25-N26 lengths decrease by $0.7 \mathrm{pm}, 1.0 \mathrm{pm}$ and $0.5 \mathrm{pm}$, respectively. And the changes in bond lengths of $\mathrm{N}-\mathrm{C}$,

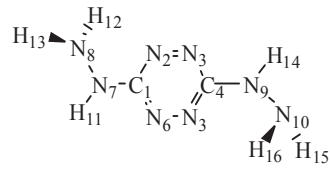

DHT

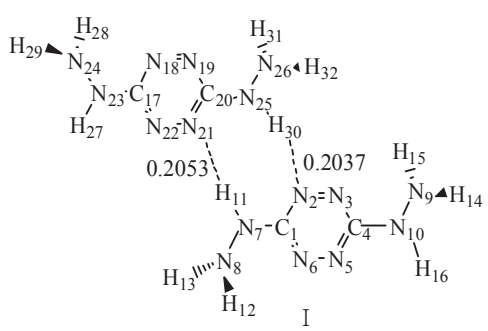

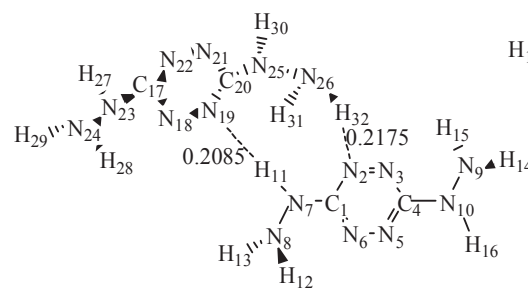

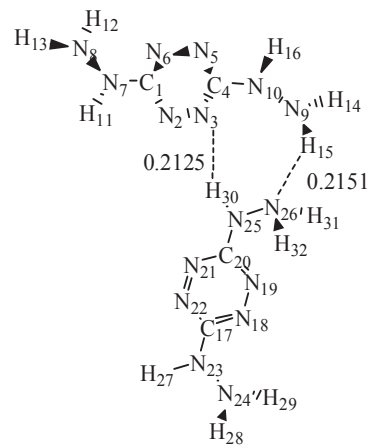

IV

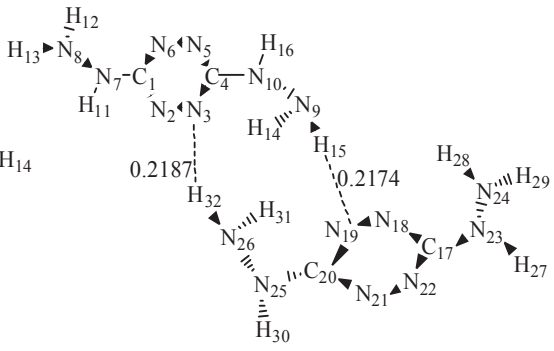

III

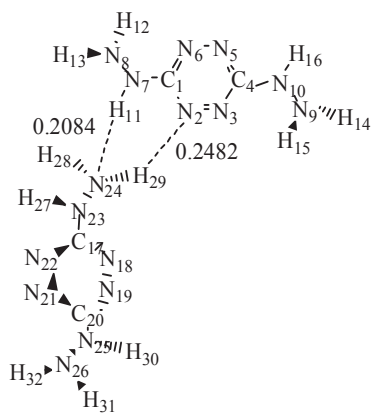

$\mathrm{V}$

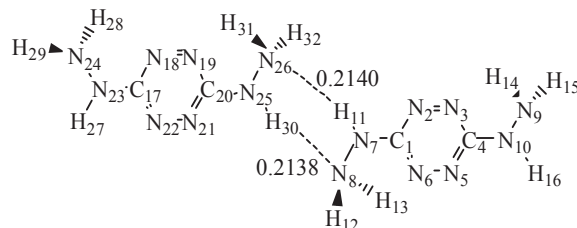

VII

Figure 1. Atomic numbering, optimized geometries and intermolecular distances (nm) of DHT and its dimers. 
Table 1. Part of fully optimized geometries of DHT and (DHT) $)_{2}$ at B3LYP/6-311++G** level $^{a}$

\begin{tabular}{ccccccccc}
\hline Parameter & DHT & I & II & III & IV & V & VI & VII \\
\hline$R(1,7)$ & 0.1371 & 0.1355 & 0.1364 & 0.1373 & 0.1372 & 0.1364 & 0.1376 & 0.1368 \\
$R(7,11)$ & 0.1010 & 0.1021 & 0.1020 & 0.1009 & 0.1010 & 0.1020 & 0.1012 & 0.1019 \\
$R(17,18)$ & $(0.1347)$ & 0.1340 & 0.1329 & 0.1330 & 0.1332 & 0.1341 & 0.1330 & 0.1333 \\
$R(17,22)$ & $(0.1346)$ & 0.1348 & 0.1363 & 0.1363 & 0.1361 & 0.1348 & 0.1363 & 0.1361 \\
$R(17,23)$ & $(0.1371)$ & 0.1375 & 0.1371 & 0.1371 & 0.1372 & 0.1375 & 0.1377 & 0.1371 \\
$R(18,19)$ & $(0.1311)$ & 0.1317 & 0.1332 & 0.1331 & 0.1329 & 0.1315 & 0.1332 & 0.1328 \\
$R(19,20)$ & $(0.1346)$ & 0.1345 & 0.1335 & 0.1335 & 0.1335 & 0.1343 & 0.1330 & 0.1335 \\
$R(20,21)$ & $(0.1347)$ & 0.1359 & 0.1367 & 0.1366 & 0.1362 & 0.1348 & 0.1362 & 0.1362 \\
$R(20,25)$ & $(0.1371)$ & 0.1360 & 0.1361 & 0.1362 & 0.1369 & 0.1376 & 0.1374 & 0.1367 \\
$R(21,22)$ & $(0.1311)$ & 0.1304 & 0.1291 & 0.1291 & 0.1294 & 0.1308 & 0.1291 & 0.1294 \\
$R(25,26)$ & $(0.1406)$ & 0.1401 & 0.1401 & 0.1402 & 0.1409 & 0.1398 & 0.1417 & 0.1410 \\
$D(1,7,8,12)$ & 78.98 & 47.66 & 43.32 & 77.73 & 78.39 & 41.70 & 94.49 & 75.74 \\
$D(1,7,8,13)$ & -37.84 & -69.32 & -73.01 & -39.30 & -38.66 & -74.74 & -21.18 & -40.15 \\
$D(11,7,8,12)$ & -131.88 & -118.23 & -110.55 & -132.99 & -132.66 & -112.99 & -127.18 & -132.29 \\
$D(11,7,8,13)$ & 111.29 & 124.79 & 133.12 & 109.98 & 110.29 & 130.58 & 117.15 & 111.82 \\
$D(20,25,26,31)$ & $(79.16)$ & -132.79 & 50.41 & 45.19 & 71.95 & -101.32 & 100.97 & 76.57 \\
$D(20,25,26,32)$ & $(-37.65)$ & 106.82 & -68.10 & -73.57 & -43.43 & 135.41 & -13.34 & -39.04 \\
$D(30,25,26,31)$ & $(-131.89)$ & 64.00 & -109.10 & -110.70 & -136.75 & 48.53 & -120.54 & -131.89 \\
$D(30,25,26,32)$ & $(111.31)$ & -56.39 & 132.39 & 130.54 & 107.87 & -74.74 & 125.15 & 112.51 \\
\hline
\end{tabular}

${ }^{a}$ Bond lengths are in nm, dihedral angles are in ${ }^{\circ}$ and values in parentheses are data of DHT.

$\mathrm{N}-\mathrm{N}$ for the tetrazine ring of the second sub-system can't even ignored, the other bond lengths of dimer II change slightly. The changes of bond lengths for dimers III, IV, VI and VII are similar to those of dimer II. The bond lengths of dimer I mainly occur on the adjacent hydrogen bond. The bond lengths of dimer $\mathrm{V}$ change less than those of the other six dimers. The bond angles of all dimers change slightly, while the dihedral angles change greatly compare with those of monomer. Such as: the change of dihedral angles for dimer VII mainly occur in the tetrazine rings, dimers III and IV's mainly occur in the tetrazine ring of one sub-system and in hydrazino groups adjacent the hydrogen bond, dimers I, II, VI and V's mainly occur in hydrazino groups adjacent the hydrogen bond (as can be seen from Table 1), which implies that the bond bending or the internal rotation of DHT molecular have occurred in the dimerization process.

Figure 1 shows that there are two H-bonds in all dimers, except for dimer VI. The H-bonding lengths usually determine the binding energies when the intermolecular contacts are similar. Judged by the intermolecular distances, it can be speculated that the intensities of interactions may be in the order: I $>$ II $>$ IV $\approx$ VII $>$ III $>$ V.

Binding energies. Table 2 shows both the uncorrected and corrected binding energies. To determine the appropriateness of the chosen basis set $\left(6-311++\mathrm{G}^{* *}\right)$ for the calculations, we have determined the binding energies with aug-cc-pVDZ basis set. The difference of the values of $(\Delta E)_{C}$ caused by using two basis set are very little. Moreover, both the corrected and uncorrected binding energies with the aug-cc-pVDZ basis set give the same stability order for the dimers as $6-311++\mathrm{G}^{* *}$ basis set, suggesting the energies are close to the basis set limit. Furthermore, to confirm the reliability of calculated results, we have determined the binding energies of the B3LYP optimized geometries by using hybird functional MPW1PW91. The diffe-

Table 2. Binding energies and zero point energies of DHT dimers $\left(\mathrm{kJ} \cdot \mathrm{mol}^{-1}\right)$ at B3LYP level

\begin{tabular}{ccrrrrrrr}
\hline Basis sets & Energy & \multicolumn{1}{c}{ I } & \multicolumn{1}{c}{ II } & III & IV & V & VI & VII \\
\hline B3LYP/ & ZPEC & 2.09 & 3.19 & 3.14 & 3.63 & 2.34 & 6.09 & 3.78 \\
6-311++G** & BSSE & 4.93 & 4.53 & 4.65 & 4.78 & 2.32 & 7.49 & 3.30 \\
& $\Delta E$ & -21.92 & -29.73 & -24.49 & -27.32 & -4.78 & -19.24 & -30.77 \\
& $(\Delta E)_{\mathrm{C}}$ & -16.98 & -25.20 & -19.83 & -22.54 & -2.46 & -11.75 & -27.47 \\
& $(\Delta E)_{\text {C. ZPEC }}$ & -14.90 & -22.01 & -16.69 & -18.92 & -0.12 & -5.66 & -23.69 \\
B3LYP/ & BSSE & 2.60 & 2.10 & 2.14 & 1.73 & 2.54 & 6.37 & 3.68 \\
Aug-cc-pVDZ & $\Delta E$ & -19.40 & -25.90 & -21.96 & -25.19 & -4.13 & -16.02 & -29.49 \\
MPW1PW91/ & $(\Delta E)_{\mathrm{C}}$ & -16.79 & -23.80 & -19.82 & -23.46 & -1.59 & -9.65 & -25.82 \\
6-311++G** & $\mathrm{BSSE}$ & 6.17 & 5.60 & 4.93 & 5.88 & 3.45 & 9.52 & 3.98 \\
& $\Delta E$ & -24.58 & -32.42 & -26.99 & -29.84 & -6.67 & -23.82 & -33.16 \\
& $(\Delta E)_{\mathrm{C}}$ & -18.41 & -26.82 & -22.06 & -23.96 & -3.22 & -14.30 & -29.18 \\
\hline
\end{tabular}


Table 3. Part of NBO charges (e) of DHT and (DHT) $)_{2}$ at B3LYP level ${ }^{a}$

\begin{tabular}{|c|c|c|c|c|c|c|c|c|}
\hline Atomic & DHT & I & II & III & IV & V & VI & VII \\
\hline $\mathrm{C} 1$ & 0.4839 & 0.4999 & 0.4948 & 0.4803 & 0.4811 & 0.4912 & 0.4851 & 0.4831 \\
\hline N2 & -0.2646 & -0.2906 & -0.2762 & -0.2358 & -0.2312 & -0.2689 & -0.2439 & -0.2320 \\
\hline N3 & -0.2374 & -0.2593 & -0.2614 & -0.2980 & -0.3045 & -0.2636 & -0.2752 & -0.2636 \\
\hline $\mathrm{C} 4$ & 0.4839 & 0.4784 & 0.4799 & 0.4954 & 0.4968 & 0.4790 & 0.4829 & 0.4808 \\
\hline N5 & -0.2646 & -0.2267 & -0.2298 & -0.2340 & -0.2337 & -0.2329 & -0.2332 & -0.2382 \\
\hline N6 & -0.2375 & -0.2605 & -0.2628 & -0.2554 & -0.2548 & -0.2654 & -0.2563 & -0.2718 \\
\hline N8 & -0.6961 & -0.6938 & -0.6954 & -0.6952 & -0.6952 & -0.6977 & -0.7178 & -0.7234 \\
\hline N9 & -0.6961 & -0.6966 & -0.6961 & -0.7068 & -0.7118 & -0.6969 & -0.7048 & -0.6957 \\
\hline H11 & 0.4214 & 0.4466 & 0.4442 & 0.4221 & 0.4242 & 0.4446 & 0.4280 & 0.4464 \\
\hline $\mathrm{H} 12$ & 0.3852 & 0.3783 & 0.3761 & 0.3859 & 0.3856 & 0.3772 & 0.3947 & 0.3958 \\
\hline H14 & 0.3779 & 0.3774 & 0.3765 & 0.3657 & 0.3664 & 0.3763 & 0.3748 & 0.3756 \\
\hline H15 & 0.3852 & 0.3854 & 0.3855 & 0.4085 & 0.4100 & 0.3844 & 0.401 & 0.3855 \\
\hline N18 & $(-0.2646)$ & -0.2668 & -0.2739 & -0.2764 & -0.2807 & -0.2659 & -0.2821 & -0.2791 \\
\hline N19 & $(-0.2374)$ & -0.2758 & -0.3196 & -0.3130 & -0.2866 & -0.2542 & -0.2866 & -0.2864 \\
\hline $\mathrm{C} 20$ & $(0.4839)$ & 0.4982 & 0.5007 & 0.4970 & 0.4829 & 0.4964 & 0.4928 & 0.4831 \\
\hline $\mathrm{N} 21$ & $(-0.2646)$ & -0.2746 & -0.2206 & -0.2218 & -0.2122 & -0.2136 & -0.2105 & -0.2187 \\
\hline N22 & $(-0.2375)$ & -0.2201 & -0.2155 & -0.2177 & -0.2254 & -0.2366 & -0.2146 & -0.2244 \\
\hline N23 & $(-0.4702)$ & -0.4723 & -0.4691 & -0.4693 & -0.4704 & -0.4719 & -0.4919 & -0.4702 \\
\hline N24 & $(-0.6961)$ & -0.6962 & -0.6960 & -0.6958 & -0.6959 & -0.7312 & -0.7073 & -0.6956 \\
\hline N25 & $(-0.4702)$ & -0.4667 & -0.4584 & -0.4591 & -0.4762 & -0.4747 & -0.4687 & -0.4778 \\
\hline N26 & $(-0.6961)$ & -0.6949 & -0.7079 & -0.7058 & -0.7198 & -0.6899 & -0.7155 & -0.7235 \\
\hline $\mathrm{H} 28$ & $(0.3852)$ & 0.3848 & 0.3853 & 0.3854 & 0.3847 & 0.3946 & 0.4032 & 0.3850 \\
\hline $\mathrm{H} 29$ & $(0.3779)$ & 0.3768 & 0.3794 & 0.3778 & 0.3761 & 0.4055 & 0.3756 & 0.376 \\
\hline $\mathrm{H} 30$ & $(0.4214)$ & 0.4472 & 0.4230 & 0.4225 & 0.4446 & 0.3987 & 0.4237 & 0.4465 \\
\hline H31 & $(0.3852)$ & 0.3778 & 0.3681 & 0.3656 & 0.3935 & 0.3710 & 0.3917 & 0.3952 \\
\hline H32 & $(0.3779)$ & 0.3812 & 0.4093 & 0.4084 & 0.3847 & 0.3854 & 0.3888 & 0.3875 \\
\hline
\end{tabular}

${ }^{a}$ Values in parentheses are data of the monomer DHT.

rences of values of $(\Delta E)_{C}$ caused by using two methods are almost within $2.55 \mathrm{~kJ} \cdot \mathrm{mol}^{-1}$, suggesting the energies are also close to the method limit. Therefore, our discussion is still based on the result of $6-311++\mathrm{G}^{* *}$. The corrected binding energy for dimer VII is $-23.69 \mathrm{~kJ} \cdot \mathrm{mol}^{-1}$, the binding energy for each hydrogen bond is $-11.85 \mathrm{~kJ} \cdot \mathrm{mol}^{-1}$, which is smaller than the best experimental estimate dissociation energy $\left(15 \mathrm{~kJ} \cdot \mathrm{mol}^{-1}\right)$ of water dimer, ${ }^{32}$ indicating that the hydrogen bonding is moderate. Both the corrected and uncorrected binding energies indicated that the stability of the dimers is in the order of VII $<$ II $<$ IV $<$ III $<$ I $<$ VI $<$ V, so the stability of the optimized dimers is VII $>$ II $>$ IV $>$ III $>$ I $>$ VI $>$ V. This order is not in consistence with that determined by the intermolecular distances. Hence, the results challenge the traditional viewpoint that the stability was determined only by hydrogen bonging. The reason for this contradiction should be that the hydrogen bonds decrease the conjugation of both the submoleculars in I and one submolecular in II, IV and III, while the conjugation of two submoleculars in VII keeps well.

Atomic charges and charge transfer. Table 3 lists the atomic NBO charges of DHT and its dimers. Compared to the monomer, atomic charges on all dimers change largely, and the change mainly occurs on the adjacent $\mathrm{N}-\mathrm{H} \cdots \mathrm{N}$ atoms of DHT dimers between submolecules and on nitrogen atoms located on tetrazine ring, while charge transfer between two subsystems is small for all seven DHT dimers. For instance, charges on the $\mathrm{H}_{11}$,
$\mathrm{H}_{30}, \mathrm{C}_{1}$ and $\mathrm{C}_{20}$ of dimer I increase by $0.025 \mathrm{e}, 0.026 \mathrm{e}, 0.022 \mathrm{e}$, 0.016 e and $0.014 \mathrm{e}$, respectively, and charges on $\mathrm{N}(2), \mathrm{N}(3)$, $\mathrm{N}(6), \mathrm{N}(19)$ and $\mathrm{N}(21)$ of tetrazine ring decrease by 0.026 , $0.022,0.023,0.038$ and $0.010 \mathrm{e}$, respectively, while charges on $\mathrm{N}(5)$ and $\mathrm{N}(22)$ increase by $0.038,0.017 \mathrm{e}$, respectively. The changes of atomic charges on dimer I are the same as those of

Table 4. Part of calculated results for (DHT) $)_{2}$ at B3LYP by NBO analysis

\begin{tabular}{|c|c|c|c|}
\hline Dimer & Donor NBO (i) & Acceptor NBO (j) & $E(2)\left(\mathrm{kJ} \cdot \mathrm{mol}^{-1}\right)$ \\
\hline \multirow[t]{2}{*}{ I } & LP (1) N21 & BD*(1) N7- H11 & 49.96 \\
\hline & $\mathrm{LP}(1) \mathrm{N} 2$ & $\mathrm{BD}^{*}(1) \mathrm{N} 25-\mathrm{H} 30$ & 54.39 \\
\hline \multirow[t]{2}{*}{ II } & LP (1) N2 & $\mathrm{BD} *(1) \mathrm{N} 26-\mathrm{H} 32$ & 31.97 \\
\hline & LP (1) N19 & BD*(1) N7- H11 & 49.75 \\
\hline \multirow[t]{2}{*}{ III } & $\mathrm{LP}(1) \mathrm{N} 3$ & $\mathrm{BD} *(1) \mathrm{N} 26-\mathrm{H} 32$ & 31.30 \\
\hline & LP (1) N19 & $\mathrm{BD} *(1) \mathrm{N} 9-\mathrm{H} 15$ & 33.30 \\
\hline \multirow[t]{2}{*}{ IV } & LP (1) N3 & $\mathrm{BD} *(1) \mathrm{N} 25-\mathrm{H} 30$ & 42.43 \\
\hline & LP (1) N26 & BD*(1) N9 - H15 & 47.03 \\
\hline \multirow[t]{2}{*}{ V } & LP (1) N2 & $\mathrm{BD} *(1) \mathrm{N} 24-\mathrm{H} 29$ & 13.81 \\
\hline & LP (1) N24 & $\mathrm{BD}^{*}(1) \mathrm{N} 7-\mathrm{H} 11$ & 54.64 \\
\hline \multirow[t]{3}{*}{ VI } & LP (1) N8 & $\mathrm{BD}^{*}(1) \mathrm{N} 24-\mathrm{H} 28$ & 26.15 \\
\hline & LP (1) N23 & BD*(1)N7 - H11 & 10.38 \\
\hline & LP (1) N26 & BD*(1)N9 - H15 & 20.84 \\
\hline \multirow[t]{2}{*}{ VII } & LP (1) N8 & $\mathrm{BD}^{*}(1) \mathrm{N} 25-\mathrm{H} 30$ & 49.04 \\
\hline & LP (1) N26 & $\mathrm{BD}^{*}(1) \mathrm{N} 7-\mathrm{H} 11$ & 49.50 \\
\hline
\end{tabular}


the other six dimers. The net result of charge transfer is that a submolecule acquires $0.003 \mathrm{e}, 0.008 \mathrm{e}, 0.001 \mathrm{e}, 0.002 \mathrm{e}, 0.02 \mathrm{e}$, $0.004 \mathrm{e}$ and $0.000 \mathrm{e}$ for dimers I, II, III, IV, V, VI and VII, respectively. There is no net charge transfer between the two submolecules of dimer VII due to the same distances of its two $\mathrm{H}$-bonds with opposite charge transfer direction. The dipole moments of DHT monomer and seven dimers are 0.067, 2.500, $0.651,0.989,0.738,3.095,1.175$ and 0.967 Debye, respectively.

Natural bond orbital analysis. Table 4 summarizes the second-order perturbative estimates of "donor-acceptor" (bond- antibond) interactions in the NBO basis for all the dimers. It was carried out by examining all possible interactions between "filled" (donor) Lewis-type NBOs and "empty" (acceptor) nonLewis NBOs, and estimating their stabilization energy by second order perturbation theory. ${ }^{33-35}$ The stabilization energies $E(2)$ are proportional to the NBO interaction intensities. When the donor and the acceptor belong to different submolecules in a cluster, we call it intermolecular NBO interaction. It is the intermolecular NBO interaction that reveals the origin of intermolecular interactions. As can be seen from the intermolecular

Table 5. The thermodynamic properties of DHT and $(\mathrm{DHT})_{2}$ at different temperatures ${ }^{a}$

\begin{tabular}{|c|c|c|c|c|c|c|c|}
\hline Structure & $\begin{array}{l}T . \\
/ \mathrm{K}\end{array}$ & $\begin{array}{c}C_{p}^{\theta} / \\
\mathrm{J} \cdot \mathrm{mol}^{-1} \cdot \mathrm{K}^{-1}\end{array}$ & $\begin{array}{c}S_{T}^{\theta} / \\
\mathrm{J} \cdot \mathrm{mol}^{-1} \cdot \mathrm{K}^{-1}\end{array}$ & $\begin{array}{c}H_{T}^{\theta}{ }_{T}^{\prime} \\
\mathrm{kJ} \cdot \mathrm{mol}^{-1}\end{array}$ & $\begin{array}{c}\Delta S_{T} / \\
\mathrm{J} \cdot \mathrm{mol}^{-1} \cdot \mathrm{K}^{-1}\end{array}$ & $\begin{array}{c}\Delta H_{T} / \\
\mathrm{kJ} \cdot \mathrm{mol}^{-1}\end{array}$ & $\begin{array}{c}\Delta G_{T} / \\
\mathrm{kJ} \cdot \mathrm{mol}^{-1}\end{array}$ \\
\hline \multirow[t]{5}{*}{ DHT } & 200.00 & 118.40 & 350.98 & 14.86 & & & \\
\hline & 298.15 & 157.04 & 405.56 & 28.41 & & & \\
\hline & 400.00 & 192.69 & 456.83 & 46.26 & & & \\
\hline & 600.00 & 244.76 & 545.58 & 90.40 & & & \\
\hline & 800.00 & 278.19 & 620.90 & 142.92 & & & \\
\hline \multirow[t]{5}{*}{ I } & 200.00 & 249.46 & 566.20 & 31.30 & -135.76 & -17.46 & 9.70 \\
\hline & 298.15 & 327.24 & 680.48 & 59.64 & -130.64 & -16.22 & 22.73 \\
\hline & 400.00 & 399.30 & 786.99 & 96.74 & -126.67 & -14.82 & 35.85 \\
\hline & 600.00 & 504.48 & 970.36 & 187.90 & -120.80 & -11.94 & 60.54 \\
\hline & 800.00 & 572.13 & 1125.42 & 296.03 & -116.38 & -8.85 & 84.26 \\
\hline \multirow[t]{5}{*}{ II } & 200.00 & 249.41 & 564.92 & 30.98 & -137.04 & -24.22 & 3.19 \\
\hline & 298.15 & 327.59 & 679.30 & 59.35 & -131.82 & -22.95 & 16.35 \\
\hline & 400.00 & 399.49 & 785.90 & 96.47 & -127.76 & -21.53 & 29.58 \\
\hline & 600.00 & 504.48 & 969.30 & 187.65 & -121.86 & -18.63 & 54.49 \\
\hline & 800.00 & 572.02 & 1124.34 & 295.77 & -117.46 & -15.55 & 78.42 \\
\hline \multirow[t]{5}{*}{ III } & 200.00 & 249.78 & 569.23 & 30.95 & -132.73 & -19.26 & 7.29 \\
\hline & 298.15 & 328.63 & 683.93 & 59.41 & -127.19 & -17.90 & 20.03 \\
\hline & 400.00 & 400.48 & 790.83 & 96.64 & -122.83 & -16.37 & 32.77 \\
\hline & 600.00 & 505.10 & 974.56 & 187.97 & -116.60 & -13.32 & 56.64 \\
\hline & 800.00 & 572.34 & 1129.74 & 296.18 & -112.06 & -10.15 & 79.50 \\
\hline \multirow[t]{5}{*}{ IV } & 200.00 & 247.90 & 570.68 & 30.85 & -131.28 & -21.62 & 4.63 \\
\hline & 298.15 & 326.67 & 684.58 & 59.10 & -126.54 & -20.47 & 17.26 \\
\hline & 400.00 & 398.89 & 790.95 & 96.15 & -122.71 & -19.12 & 29.96 \\
\hline & 600.00 & 504.20 & 974.18 & 187.24 & -116.98 & -16.31 & 53.88 \\
\hline & 800.00 & 571.88 & 1129.17 & 295.32 & -112.63 & -13.27 & 76.83 \\
\hline \multirow[t]{5}{*}{ V } & 200.00 & 248.45 & 585.81 & 31.22 & -116.15 & -0.84 & 22.39 \\
\hline & 298.15 & 327.37 & 699.95 & 59.54 & -111.17 & 0.38 & 33.52 \\
\hline & 400.00 & 399.80 & 806.56 & 96.67 & -107.10 & 1.81 & 44.65 \\
\hline & 600.00 & 505.03 & 990.15 & 187.94 & -101.01 & 4.80 & 65.40 \\
\hline & 800.00 & 572.49 & 1145.35 & 296.16 & -96.45 & 7.98 & 85.14 \\
\hline \multirow[t]{5}{*}{ VI } & 200.00 & 245.41 & 536.82 & 29.86 & -165.14 & -12.47 & 20.55 \\
\hline & 298.15 & 324.83 & 649.85 & 57.90 & -161.27 & -11.53 & 36.55 \\
\hline & 400.00 & 397.60 & 755.76 & 94.79 & -157.90 & -10.34 & 52.82 \\
\hline & 600.00 & 503.52 & 938.60 & 185.70 & -152.56 & -7.71 & 83.82 \\
\hline & 800.00 & 571.45 & 1093.43 & 293.67 & -148.37 & -4.78 & 113.91 \\
\hline \multirow[t]{5}{*}{ VII } & 200.00 & 247.32 & 567.97 & 30.85 & -133.99 & -24.79 & 2.00 \\
\hline & 298.15 & 325.67 & 681.53 & 59.02 & -129.59 & -23.72 & 14.92 \\
\hline & 400.00 & 398.01 & 787.62 & 95.97 & -126.04 & -22.47 & 27.95 \\
\hline & 600.00 & 503.71 & 970.57 & 186.93 & -120.59 & -19.79 & 52.56 \\
\hline & 800.00 & 571.64 & 1125.46 & 294.94 & -116.34 & -16.82 & 76.25 \\
\hline
\end{tabular}


NBO interaction in Table 4, the main NBO interacting in the DHT dimers are that the lone pair on nitrogen of one submolecular acts as donor and that the N-H antibond of another submolecular as acceptor. Two lone pairs of each nitrogen interact with $\mathrm{N}-\mathrm{H}$ antibonds in dimers I, II, III, IV, V and VII, and the total stabilization energies of these two NBO interactions are over $60 \mathrm{~kJ} \cdot \mathrm{mol}^{-1}$, forming a strong hydrogen bond. While the total stabilization energies of three nitrogen lone pairs with N-H antibonds in dimer VI is relatively small, forming hydrogen bonds with moderate strength.

Thermodynamic properties. On the basis of vibrational analysis and statistical thermodynamic method, the standard thermodynamic functions, entropies $\left(S_{\mathrm{m}}^{\theta}\right)$ and enthalpies $\left(H_{\mathrm{m}}^{\theta}\right)$, were obtained and listed in Table 5. Both the entropy and the enthalpy change for the dimerization process are negative throughout the temperature range from 200.0 to $800.0 \mathrm{~K}$, except for dimer $\mathrm{V}$. The intermolecular interaction is, therefore, an exothermic process accompanied by a decrease in the entropy. The values of $C_{p}^{\theta}$ for all the dimers are close to each other at the same temperatures, with values larger than the double $C^{\theta}{ }_{p}$ of monomer by $8.61-16.11 \mathrm{~J} \cdot \mathrm{mol}^{-1} \cdot \mathrm{K}^{-1}$. The values of $\left(\Delta H_{T}\right)$ for each dimer at the same temperature give the same sequence $\left(\Delta H_{T}\right)_{\mathrm{VII}}<\left(\Delta H_{T}\right)_{\mathrm{II}}<\left(\Delta H_{T}\right)_{\mathrm{IV}}<\left(\Delta H_{T}\right)_{\mathrm{III}}<\left(\Delta H_{T}\right)_{\mathrm{I}}<\left(\Delta H_{T}\right)_{\mathrm{VI}}<$ $\left(\Delta H_{T}\right)_{\mathrm{V}}$ as the binding energies. The change of Gibbs free energies $\left(\Delta G_{T}=\Delta H_{T}-T \Delta S_{T}\right)$ during the dimerization processes for all dimers are positive under $200.0 \mathrm{~K}$. This indicates that all the dimerization processes can't spontaneously occur under $200 \mathrm{~K}$. The stability order of the dimers under $400 \mathrm{~K}$ keeps as VII $>$ II $>$ IV $>$ III $>$ I $>$ VI $>$ V, judged by the values of $\Delta G_{T}$. The $\Delta G_{T}$ value increases as temperature increases for each dimer, thus the interactions weaken as temperature increases. The $\Delta G_{T}$ value gives a different stability order over $400 \mathrm{~K}$, since the value of $\Delta H_{T}$ is less sensitive to temperature than that of $T \Delta S$, the effect of temperature upon $\Delta G_{T}$ is derived from the contributions of $T \Delta S$ term for the same dimer.

\section{Conclusion}

The corrected binding energy of the most stable dimer VII is predicted to be $-23.69 \mathrm{~kJ} \cdot \mathrm{mol}^{-1}$, which is smaller than that of water dimer, indicating that the hydrogen bonding of $(\mathrm{DHT})_{2}$ is moderate. The bond bending or the internal rotation of DHT dimers have occurred in the dimerization process, and they are mainly occurred in hydrazino groups adjacent the hydrogen bond. The interaction is an exothermic process along with the decreases of entropies, the free energy differences between the monomer and dimers decrease as the temperature decreases, the dimerization process of (DHT) $)_{2}$ can not occur spontaneously at given temperatures.

Acknowledgments. This work is supported by the National Natural Science Foundation of China (20603026, 21073141), the Natural Science Foundation of Shaanxi Province (2009 JQ2002) and NWU Graduate Experimental Research Funds (09YSY23).

\section{References}

1. Hiskey, M.; Goldman, N.; Stine, J. J. Energ. Mater. 1998, 16, 119.

2. Paine, R. T.; Koestle, W.; Borek, T. J. Inorg. Chem. 1999, 38, 3738.

3. Talawar, M. B.; Sivabalan, R.; Senthilkumar, N. J. Hazard. Mater. 2004, 113, 11 .

4. Yang, S. Q.; Yue, S. T. Chinese Journal of Energetic Materials 2003, 11, 231.

5. Yang, S. Q.; Xu, S. L.; Lei, Y. P. Chinese Journal of Energetic Materials 2006, 14, 475.

6. Zhou, Y. Master Dissertation. Mianyang: China Academy of Engineering Physics; 2007.

7. Chavez, D. E.; Hiskey, M. A.; Naud, D. J. Pyrotech. 1999, 10, 17.

8. Nurullah, S. Tetrahedron 2007, 63, 4199.

9. Marcus, H. J. Tetrazine Compounds. US Patent 3244702. 1966.

10. Chavez, D. E.; Hiskey, M. A. J. Energ. Mater. 1999, 17, 357.

11. Li, X. T.; Pang, S. P.; Yu, Y.Z.; Luo, Y. J. Acta Chim. Sin. 2007, 65, 971.

12. Pan, J.; He, J. X.; Tao, Y. J. Chinese Journal of Energetic Materials 2006, 14, 116.

13. Yang, S. Q.; Xu, S. L. Chinese Research and Application 2006, 18, 320.

14. Xu, S. L.; Yang, S. Q.; Zhang, W.; Zhang, Jouranl of National University of Denfense Technology 2006, 28, 17.

15. Chavez, D. E.; Hiskey, M. A. Journal of Energetic Materials 1999, $17,357$.

16. Chavez, D. E.; Hiskey, M. A. Heterocycl. Chem. 1998, 35, 1329.

17. Pagoria, P. F.; Lee, G. S.; Mitchell, A. R.; Schmidt, R. D. Thermochimica Acta 2002, 384, 187.

18. Oxley, J. C.; Smith, J. L.; Chen, H. Thermochimica Acta 2002, 384,91

19. Jadhav, H. S.; Dhavale, D. D.; Krishnamurthy, V. V. Theory and Practice of Energetic Materials 2001, 493.

20. Xu, K. Z.; Zhao, F. Q.; Ren, Y. H.; Ma, H. X.; Song, J. R.; Hu, R. Z. Acta Phys. Chim. Sin. 2009, 25, 309.

21. Tan, J. Z.; Xiao, H. M.; Gong, X. D. Acta Chim. Sinica 2002, 60, 200.

22. Ju, X. H.; Xiao, H. M. J. Mol. Struct. Theochem. 2002, 588, 79.

23. Ju, X. H.; Xiao, J. J.; Xiao, H. M. J. Mol. Struct. Theochem. 2003, $626,231$.

24. Ma, H. X.; Xiao, H. M.; Song, J. R.; Ju, X. H.; Zhu, W.; Yu, K. B. Chemical Physics 2008, 344, 79.

25. Xiao, H. M.; Ju, X. H.; Xu, L. N.; Fang, G. Y.J. Chem. Phys. 2004, $121,12523$.

26. Fletcher, R.; Powell, M. J. D. Comput. J. 1963, 6, 163.

27. Schlegel, H. B. J. Comput. Chem. 1982, 3, 124.

28. Boys, S. F.; Bernardi, F. Mol. Phys. 1970, 19, 553.

29. Johnson, A.; Kollman, P.; Rothenberg, S. Thermochim. Acta 1973, 29,167

30. Chalasinski, G.; Szczesniak, M. M. Mol. Phys. 1988, 63, 205.

31. Frisch, M. J.; Trucks, G. W.; Schlegel, H. B.; Gill, P. M. W.; Johnson, B. G.; Robb, M. A.; Cheeseman, J. R.; Keith, T.; Petersson, G. A.; Montgomery, J. A.; Raghavachari, K.; Al-Laham, M. A.; Zakrzewski, V. G.; Ortiz, J. V.; Fores-man, J. B.; Cioslowski, J.; Stefanov, B. B.; Nanayakkara, A.; Challacombe, M.; Peng, C. Y.; Ayala, P. Y.; Chen, W.; Wong, M. W.; Andres, J. L.; Replogle, E. S.; Gomperts, R.; Martin, R. L.; Stewart, J. P.; Head-Gordon, M.; Gonzalez, C.; Pople, J. A. Gaussian 98, Revision A. 7, Gaussian, Inc., Pittsburgh PA, 1998

32. Feyereisen, M. W.; Feller, D.; Dixon, D. A. J. Phys. Chem. 1996, 100, 2993.

33. Reed, A. E.; Weinstock, R. B.; Weinhold, F. J. Chem. Phys. 1985, 83,735 .

34. Reed, A. E.; Weinhold, F. J. Chem. Phys. 1985, 83, 1736.

35. Reed, A. E.; Curtiss, L. A.; Weinhold, F. Chem. Rev. (Washington, DC) $1988,88,899$. 